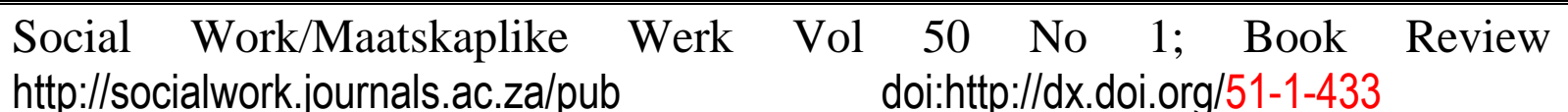

Management and Supervision of Social Workers, edited by L.K. Engelbrecht, 2014 Andover: Cengage Learning EMEA, (242 pp, ISBN:968-1-4080-8210-2)

Prof Adrian D van Breda, Department of Social Work, University of Johannesburg, Johannesburg, South Africa 



\section{BOOK REVIEW: MANAGEMENT AND SUPERVISION OF SOCIAL WORKERS, EDITED BY L.K. ENGELBRECHT, 2014. Andover: Cengage Learning EMEA, (242 pp, ISBN:968-1-4080-8210-2).}

\section{Prof Adrian D van Breda, Department of Social Work, University of Johannesburg, Johannesburg, South Africa}

This timely edited volume fills an important gap in the market - a comprehensive survey of both management and supervision, within the social work and social welfare contexts, in South Africa in light of the social development paradigm. This is a daunting undertaken, as any one of these topics would justify book-length treatment. As a result, the book is necessarily a survey rather than an in-depth interrogation. Nevertheless, by assembling a wide array of experts in South Africa (as well as a handful of international authors), each focused on a particular facet of the discussion, Engelbrecht has produced a highly readable and useful text.

Leila Patel opens the book with a neat introduction to the developmental perspective and its relevance for management and supervision. This sets the course for the eight chapters that address social work management. Rankin and Engelbrecht outline social service organisations as the context for management, giving a useful typology of government and non-governmental organisations that provide welfare services in South Africa. They contrast the approach to management of businesses and social service organisations, and give particular attention to the governance of non-profit organisations.

The following chapters provide focused attention on management theories, skills and functions. Engelbrecht and Terblanche provide a critical overview of several management theories that are, in various ways, consonant with a developmental approach to social welfare, including general systems theory, an empowerment approach and the strengths perspective. Reyneke presents a range of management skills, with particular attention to communication skills. In addition, he discusses the complexities of authority and power in management. Nel gives an overview of the four classic management functions: plan, organise, lead and control. I found her presentation of appreciative leadership particularly interesting.

Four chapters are devoted to management tasks, showing this book's commitment to not just providing an overview of management, but also offering readers practicable knowledge and tools for management. Pretorius addresses several essential management tasks, including the management of workload, risk and change. Herbst provides an overview of project management, giving particular attention to funding within the South African context and the technical aspects of writing a funding proposal. De Jager presents the chapter on human resource management. She provides a most relevant section on the recruitment and management of volunteers. Finally, Smit's comparatively detailed chapter on financial management speaks to the NPO sector and fund raising. He provides practical guidelines on budgeting and reporting.

The next four chapters focus on social work supervision. The lengthy opening chapter surveys the terrain of supervision. Engelbrecht critically engages with various 
fundamentals of supervision from a firm basis in the South African and developmental social welfare contexts, thoughtfully commenting on the risks of managerial approaches to supervision rather than his preferred life-long learning approach. He locates supervision in historical and local contexts, reviews the goals, definition, functions and roles of supervision, and discusses factors that may hinder effective supervision. In the following chapter Engelbrecht translates these fundamentals into practical guidelines for supervision, using a process model for supervision. I enjoyed the tools for developing the reflective capacity of supervisees as well as Engelbrecht's proposal for a developmental approach to supervision in which he challenges the widely held view that social workers should rapidly 'graduate' off supervision onto consultation.

Jacques discusses the three central functions of supervision: education, support and administration, providing accessible and relevant details on, for example, performance management. Like Engelbrecht, she draws on research conducted locally (in Botswana), which significantly enriches the usefulness of this chapter. Finally, Simpson and Ranigo address the supervision of social work students. They open with a situational analysis of field instruction and student supervision in South Africa, which resonated strongly with me, as a head of department trying to float a field instruction programme. They then provide practicable, process-oriented guidelines both for managing field instruction programmes and for student supervision.

The final five chapters address some contemporary cross-cutting debates in social work supervision and management. These chapters challenge the reader to step off the familiar onto new paths. Pullen-Sansfaçon introduces the concept of 'virtue ethics', in which ethics are embedded in one's conception of a 'virtuous' or 'good' person, rather than in codes or rules, and applies this to the complexities of real-world developmental social work practice. Engelbrecht, Abdullah and Herselman's brief chapter on antidiscriminatory approaches to supervision and management focuses primarily on cultural differences between supervisors/managers and supervisees/workers. The authors construct an inventory of cultural differences that could be used to develop mutual understanding and appreciation in supervision and management relationships. Martin provides an overview of emotional intelligence (the capacity to recognise, use, understand and manage one's emotions) and outlines how this can enhance supervisory and management practice. Roestenburg provides an in-depth review of the use of evidence-based practice, ecometric processes, observation, quantitative tools and digital technologies in social work practice, showing how these tools can be useful in management and supervision. Spolander closes the book with a critical examination of neoliberalism and its impact on social welfare services, particularly in relation to the developmental approach and ideals.

I found this book to be highly accessible. It gives particular attention to the NPO and social service sector within the South African context, and is easy to read and practical. The chapters are well referenced, pointing the reader to additional literature. The high point for me was Engelbrecht's two chapters on supervision, in which the author's own insights emerge most strongly. The social development paradigm is present throughout the book, but rather recessed; I would have liked more explicit, foregrounded analysis of 
the application of management and supervision in relation to the social development approach.

This book will be highly useful in social work education, at both bachelor and postgraduate levels. This could serve fruitfully as the primary textbook for courses on management and/or supervision, while specific chapters (e.g. Pullen-Sansfaçon's chapter on virtue ethics or Roestenburg's chapter on ecometrics) could be invaluable readings for other modules (in this case, ethics and assessment respectively). 